\title{
A Two-Parameter Model: Properties and Estimation under Ranked Sampling
}

\author{
Rashad Bantan ${ }^{1}$, Mahmoud Elsehetry ${ }^{2}{ }^{\oplus}$, Amal S. Hassan ${ }^{3}$, Mohammed Elgarhy ${ }^{4} \oplus$, Dreamlee Sharma ${ }^{5}$, \\ Christophe Chesneau ${ }^{6}$ and Farrukh Jamal ${ }^{7, *}$ (i)
}

check for

updates

Citation: Bantan, R.; Elsehetry, M.; Hassan, A.S.; Elgarhy, M.; Sharma, D.; Chesneau, C.; Jamal, F. A

Two-Parameter Model: Properties and Estimation under Ranked Sampling. Mathematics 2021, 9, 1214. https:// doi.org/10.3390/math9111214

Received: 7 April 2021

Accepted: 24 May 2021

Published: 27 May 2021

Publisher's Note: MDPI stays neutral with regard to jurisdictional claims in published maps and institutional affiliations.

Copyright: (c) 2021 by the authors. Licensee MDPI, Basel, Switzerland. This article is an open access article distributed under the terms and conditions of the Creative Commons Attribution (CC BY) license (https:// creativecommons.org/licenses/by/ $4.0 /)$.
Deanship of Scientific Research, King Abdulaziz University, Jeddah 21589, Saudi Arabia; rbantan@kau.edu.sa

2 Deanship of Information Technology, King Abdulaziz University, Jeddah 21589, Saudi Arabia; ma_sehetry@hotmail.com

3 Faculty of Graduate Studies for Statistical Research, Cairo University, Giza 12613, Egypt; dr.amalelmoslamy@gmail.com

4 The Higher Institute of Commercial Sciences, Al Mahalla Al Kubra, Algharbia 31951, Egypt; m_elgarhy85@sva.edu.eg

5 Department of Mathematics, Adamas University, Kolkata 700020, India; dreamleesharma@yahoo.in

6 Department of Mathematics, LMNO, University of Caen, CEDEX, 14032 Caen, France; christophe.chesneau@unicaen.fr

7 Department of Statistics, The Islamia University of Bahawalpur, Punjab 63100, Pakistan

* Correspondence: farrukh.jamal@iub.edu.pk; Tel.: +92-321-680-2194

\begin{abstract}
This study introduces a flexible model with two parameters by combining the type II half-logistic-G family with the inverted Topp-Leone distribution. The proposed model is referred to as the half logistic inverted Topp-Leone (HLITL) distribution. The associated probability density function can be considered a mixture of the inverted Topp-Leone distributions. The proposed model can be deemed an acceptable model for fitting the right-skewed, reversed J-shaped, and unimodal data. The statistical properties, including the moments, Bonferroni and Lorenz curves, Rényi entropy, and quantile function, are derived. Additionally, the plots of the skewness and kurtosis measures are plotted based on the quantiles. The parameter estimators are implemented using the maximum likelihood method based on two sampling schemes: the simple random sample method and the ranked set sampling method. The proposed method is evaluated by using simulations. The results show that the maximum likelihood estimates of the parameters under ranked set sampling are more accurate than those under simple random sampling. Generally, there is good agreement between the theoretical and empirical results. Two real datasets are used to compare the HLITL model with the following models: alpha power exponential, alpha power Lindley, odd Fréchet inverse exponential, and odd Fréchet inverse Rayleigh models. The comparison results show that the HLITL model represents a better alternative lifetime distribution than the other competitive distributions.
\end{abstract}

Keywords: type II half-logistic-G class; inverted Topp-Leone distribution; maximum likelihood method; ranked set sampling

\section{Introduction}

The Topp-Leone (TL) distribution, also known as the J-shaped distribution, is a significant model that possesses a bathtub-shaped hazard rate. The probability density function (PDF) and cumulative distribution function (CDF) of the TL distribution with a shape parameter, respectively, are given by

$$
\begin{gathered}
f(y ; \theta)=2 \theta y^{\theta-1}(1-y)(2-y)^{\theta-1}, 0 \leq y \leq 1, \theta>0, \\
F(y ; \theta)=y^{\theta}(2-y)^{\theta} .
\end{gathered}
$$

Significant properties of the TL distribution were discussed in [1]. The TL distribution was analyzed in many studies [2-4]. The inverted (or inverse) distributions are formally 
regarded as inverse transforms of random variables. The inverted distributions have different densities and hazard rate shapes from the associated noninverted distributions. The usefulness and applicability of inverted distributions have been used in various fields, such as survey sampling, biological sciences, life testing problems, and engineering sciences. In the literature, various inverted distributions and their applications in many areas have been studied [5-10].

In [11], the inverted Topp-Leone (ITL) was proposed using the transformation $X=\frac{1}{Y}-1$, where $Y$ denotes a random variable with the CDF and PDF that are, respectively, defined as

$$
\begin{gathered}
G(x ; \theta)=1-\frac{(1+2 x)^{\theta}}{(1+x)^{2 \theta}}, x, \theta>0, \\
g(x ; \theta)=\frac{2 \theta x(1+2 x)^{\theta-1}}{(1+x)^{2 \theta+1}}, x, \theta>0,
\end{gathered}
$$

where $\theta$ is the shape parameter and $\theta>0$. In [11], several properties and the estimation of the parameter of the ITL distribution were discussed based on censored samples. Recently, serious efforts have been put into developing new families of continuous probability distributions that extend the classical ones. These extended distributions have more additional parameters as well as enhanced flexibility in modeling a variety of data (see [12-17]). In [18], a highly flexible extended family, called Marshall-Olkin-G (MO-G), was proposed, and its PDF is expressed as

$$
f(x ; \delta)=\frac{\delta g(x)}{\{1-\bar{\delta}(\bar{G}(x))\}^{2}}
$$

where $\bar{\delta}=1-\delta$ and $\bar{G}(x)$ is the survival function (SF) of a baseline distribution with CDF $G(x)$, and PDF $g(x)$. Several new families that are related to the MO-G family have been considered in recent studies. This study considers the univariate family generated by a half-logistic random variable, as presented in [19]. The CDF of the HL-G family approaches that of the MO-G family. It is specified as follows:

$$
F(x ; \lambda)=2[G(x)]^{\lambda}\left\{1+[G(x)]^{\lambda}\right\}^{-1}, x>0, \lambda>0,
$$

where $\lambda$ is the shape parameter. For $\lambda=1$ in Equation (6) and $\delta=0.5$ in Equation (5), the HL-G and MO-G families coincide. The CDF given by Equation (6) extends several flexible distributions as specific cases in their skewness and kurtosis, as presented in [20-24].

In [25], the ranked set sampling (RSS) scheme was provided as another sampling technique for simple random sampling (SRS) in situations where the measurement of the variable of interest is costly or difficult to conduct. The RSS protocol is more suitable than the SRS protocol. To obtain an RSS sample, the following steps are performed:

- Draw $m$ random samples with a size $n$ from the desired population such that $m=n$;

- Without taking any measurements, rank the samples in each dataset according to the criterion determined by the experimenter;

- Choose a sample for true judgment by involving the smallest ordered unit in the first set and the second-smallest ordered unit in the second set. The operation is continued in this manner until the largest-ranked unit is chosen from the final set;

- To collect a sample of a size of $m k$ units, the above operations of the "cycle" may be repeated $k$ times. For more studies about RSS, we may refer to [26-30].

This paper proposes a more flexible model for the ITL distribution by inducing one extra shape parameter for enhancing the goodness-of-fit to the real data. The main motivation for introducing the half-logistic inverted Topp-Leone (HLITL) is as follows: (1) obtain a more flexible PDF for right-skewed, unimodal, and reversed J-shaped data; (2) provide decreasing, increasing, and upside-down hazard rate shapes; (3) estimate the 
HLITL distribution parameters on the basis of SRS and RSS; and (4) provide significant improvement in the data modeling.

The rest of the article is organized as follows. Section 2 defines the PDF, CDF, and hazard rate function (HRF) of the HLITL distribution. Section 3 derives the structural properties of the HLITL distribution. Section 4 presents the maximum likelihood (ML) parameter estimators as well as the simulation study of SRS and RSS. Section 5 describes the real data analysis. Section 6 concludes the paper.

\section{HLITL Model Characterizations}

The ITL distribution, having the CDF and PDF defined by Equations (3) and (4), respectively, was presented in [11]. This study considers the HLITL distribution as presented in Definition 1.

Definition 1. A random variable $X$ is assumed to have the HLITL distribution if its PDF is represented as follows:

$$
f(x ; \lambda, \theta)=4 \lambda \theta x(1+x)^{-2 \theta-1}(1+2 x)^{\theta-1}[1-H]^{\lambda-1}\left[1+[1-H]^{\lambda}\right]^{-2}, x>0, \lambda, \theta>0,
$$

where $H=(1+x)^{-2 \theta}(1+2 x)^{\theta}, \lambda$ and $\theta$ denote the shape parameters. A random variable with the PDF given by Equation (7) is denoted by $\sim(\lambda, \theta)$. For $\lambda=1$ in Equation (7), a new distribution called the Marshall-Olkin ITL distribution with $\delta=0.5$ is obtained. The PDF plots of the HLITL distribution for some specific values of $\lambda$ and $\theta$ are displayed in Figure 1. The shape of the HLITL distribution is unimodal, positively skewed, and reverse J-shaped.
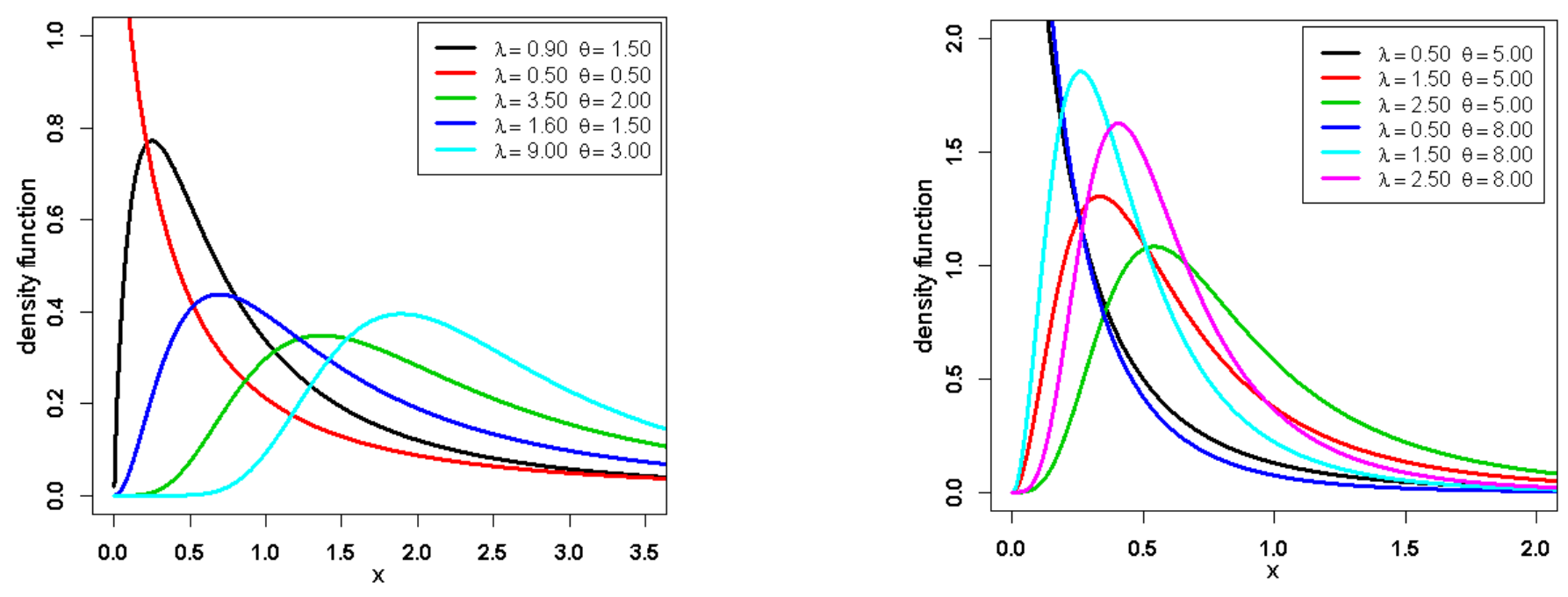

Figure 1. The PDF plots of the HLITL distribution for certain choices of parameters.

The associated CDF and HRF, respectively, are given by

$$
\begin{gathered}
F(x ; \lambda, \theta)=2[1-H]^{\lambda}\left\{1+[1-H]^{\lambda}\right\}^{-1}, \quad x, \lambda, \theta>0, \\
\tau(x ; \lambda, \theta)=4 \lambda \theta x(1+x)^{-2 \theta-1}(1+2 x)^{\theta-1}[1-H]^{\lambda-1}\left[1-[1-H]^{2 \lambda}\right]^{-1} .
\end{gathered}
$$
Figure 2.

The HRF plots for specific values of parameters with various shapes are illustrated in 

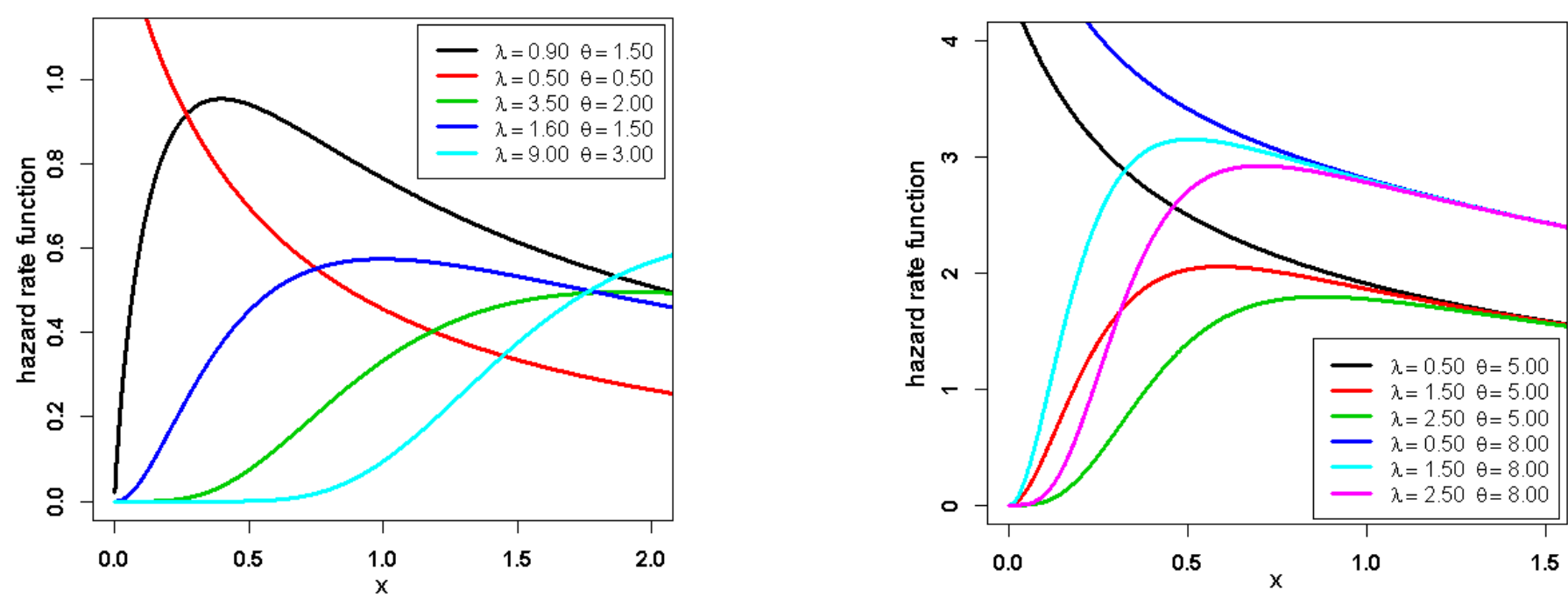

Figure 2. The HRF plots of the HLITL distribution for certain choices of $\lambda$ and $\theta$.

\section{Basic Properties of the HLITL Distribution}

The basic properties of the HLITL distribution, including moments, skewness, kurtosis, Rényi entropy, stochastic ordering, and Bonferroni and Lorenz curves, are derived in the following sections.

\subsection{Useful Representation}

The properties of the HLITL distribution are deduced through simple elicitation of its PDF. According to [19], the PDF given by Equation (7) can be represented as

$$
f(x ; \lambda, \theta)=\sum_{i=0}^{\infty} 4 \lambda(-1)^{i}(i+1) \theta x \frac{(1+2 x)^{\theta-1}}{(1+x)^{2 \theta+1}}\left[1-\frac{(1+2 x)^{\theta}}{(1+x)^{2 \theta}}\right]^{\lambda(i+1)-1} .
$$

Employing the binomial expansions, the PDF of the HLITL distribution becomes

$$
f(x ; \lambda, \theta)=\sum_{i, d=0}^{\infty} 4 \theta \lambda(-1)^{i+d}(i+1)\left(\begin{array}{c}
\lambda(i+1)-1 \\
d
\end{array}\right) x(1+x)^{-2(d+1) \theta-1}(1+2 x)^{\theta(d+1)-1},
$$

which further leads to

$$
f(x ; \lambda, \theta)=\sum_{i, d=0}^{\infty} W_{i, d} g(x ; \theta(d+1)),
$$

where $W_{i, d}=2 \lambda(-1)^{i+d} \frac{(i+1)}{d+1}\left(\begin{array}{c}\lambda(i+1)-1 \\ d\end{array}\right)$.

The PDF $g(x ; \theta(d+1))$ represents the ITL PDF with the shape parameter $\theta(d+1)$. Thus, the PDF of the HLITL distribution can be expressed as an infinite linear combination of ITL PDFs.

\subsection{HLITL Entropy}

The Rényi entropy of a random variable $X$ with the HLITL distribution for $\varphi>0$ and $\varphi \neq 1$ is expressed as

$$
I_{e}(x)=(1-\varphi)^{-1} \log \left(\int_{0}^{\infty}(f(x ; \lambda, \theta))^{\varphi} d x\right)
$$


Substituting Equation (7) into Equation (13) leads to

$$
\begin{gathered}
I_{e}=(1-\varphi)^{-1} \log \left(\sum_{c=0}^{\infty} v_{c} \int_{0}^{\infty} x^{\varphi}(1+x)^{-\varphi(2 \theta+1)}(1+2 x)^{\varphi(\theta-1)}(1-H)^{\phi(\lambda-1)+\lambda c} d x\right) \\
\text { where } v_{c}=(4 \lambda \theta)^{\varphi}(-1)^{c}\left(\begin{array}{c}
2 \varphi+c-1 \\
c
\end{array}\right) \text {. By applying the binomial expansions to } \\
\text { Equation }(14) \text {, we get } \\
I_{e}=(1-\varphi)^{-1} \log \left(\sum_{c, d, k=0}^{\infty} v_{c}(-1)^{d}\left(\begin{array}{c}
\varphi(\lambda-1)+\lambda c \\
d
\end{array}\right)\left(\begin{array}{c}
\theta(\varphi+d)-\varphi \\
k
\end{array}\right) \mathrm{B}(\varphi+k+1, \theta(\varphi+d)+\varphi-1)\right)
\end{gathered}
$$

where $\mathrm{B}(.,$.$) stands for the beta function. The numerical results of I_{e}$ of the HLITL distribution for some $\varphi, \lambda$, and $\theta$ values are listed in Table 1.

Table 1. Numerical results of Rényi entropy for the HLITL distribution.

\begin{tabular}{lccc}
\hline \multicolumn{1}{c}{ Parameters } & $\boldsymbol{\varphi}=\mathbf{0 . 5}$ & $\boldsymbol{\varphi}=\mathbf{1 . 5}$ & $\boldsymbol{\varphi}=\mathbf{2 . 5}$ \\
\hline$\theta=5, \lambda=0.5$ & 0.245 & -0.193 & -0.321 \\
$\theta=5, \lambda=1$ & 0.386 & 0.06 & -0.022 \\
$\theta=5, \lambda=1.5$ & 0.449 & 0.141 & 0.064 \\
$\theta=5, \lambda=2$ & 0.486 & 0.186 & 0.111 \\
$\theta=5, \lambda=2.5$ & 0.513 & 0.216 & 0.142 \\
$\theta=5, \lambda=3$ & 0.533 & 0.239 & 0.165 \\
$\theta=8, \lambda=0.5$ & 0.043 & -0.321 & -0.437 \\
$\theta=8, \lambda=1$ & 0.167 & -0.095 & -0.167 \\
$\theta=8, \lambda=1.5$ & 0.216 & -0.031 & -0.099 \\
$\theta=8, \lambda=2$ & 0.244 & 0.0022 & -0.065 \\
$\theta=8, \lambda=2.5$ & 0.263 & 0.023 & -0.044 \\
$\theta=8, \lambda=3$ & 0.277 & 0.038 & -0.029 \\
$\theta=10, \lambda=0.5$ & -0.041 & -0.38 & -0.491 \\
$\theta=10, \lambda=1$ & 0.076 & -0.165 & -0.233 \\
$\theta=10, \lambda=1.5$ & 0.121 & -0.107 & -0.172 \\
$\theta=10, \lambda=2$ & 0.145 & -0.078 & -0.143 \\
$\theta=10, \lambda=2.5$ & 0.161 & -0.061 & -0.125 \\
\hline
\end{tabular}

We conclude from Table 1 that as the value of shape parameter $\theta$ increased, for the same value of parameter $\lambda$, the value of randomness decreased. In addition, as the value of $\varphi$ increased, the value of randomness decreased for fixed values of $\theta$ and $\lambda$. Furthermore, the values in Table 1 are in the interval $[-0.321,0.533]$, meaning that $\lambda$ and $\theta$ had pivotal effects on the information amount. Thus, these parameters had a strong effect on the Rényi entropy, showing different degrees of uncertainty.

\subsection{Quantile Function}

The quantile function of $X \sim \operatorname{HLITL}(\lambda, \theta)$ is given as $q$ in $(0,1)$ as

$$
Q(q ; \lambda, \theta)=-V+\sqrt{V^{2}-V}, \quad V=1-\left[1-\left\{\frac{q}{2-q}\right\}^{\frac{1}{\lambda}}\right]^{\frac{-1}{\theta}} .
$$

Setting $q=0.5$ in Equation (16), we get the median $M$ of the HLITL distribution. Furthermore, by setting $q=0.25$ and 0.75 in Equation (16), the 25th and 75th percentiles are obtained, respectively. Based on the quantiles, Bowley's skewness is given by 


$$
B o=\frac{Q\left(\frac{3}{4} ; \lambda, \theta\right)-2 Q\left(\frac{1}{2} ; \lambda, \theta\right)+Q\left(\frac{1}{4} ; \lambda, \theta\right)}{Q\left(\frac{3}{4} ; \lambda, \theta\right)-Q\left(\frac{1}{2} ; \lambda, \theta\right)} .
$$

Moor's kurtosis is given by

$$
M o=\frac{Q\left(\frac{7}{8} ; \lambda, \theta\right)-Q\left(\frac{5}{8} ; \lambda, \theta\right)-Q\left(\frac{3}{8} ; \lambda, \theta\right)+Q\left(\frac{1}{8} ; \lambda, \theta\right)}{Q\left(\frac{6}{8} ; \lambda, \theta\right)-Q\left(\frac{2}{8} ; \lambda, \theta\right)}
$$

The Bo and Mo plots of the HLITL distribution were obtained based on the quantile function, shown in Figure 3.
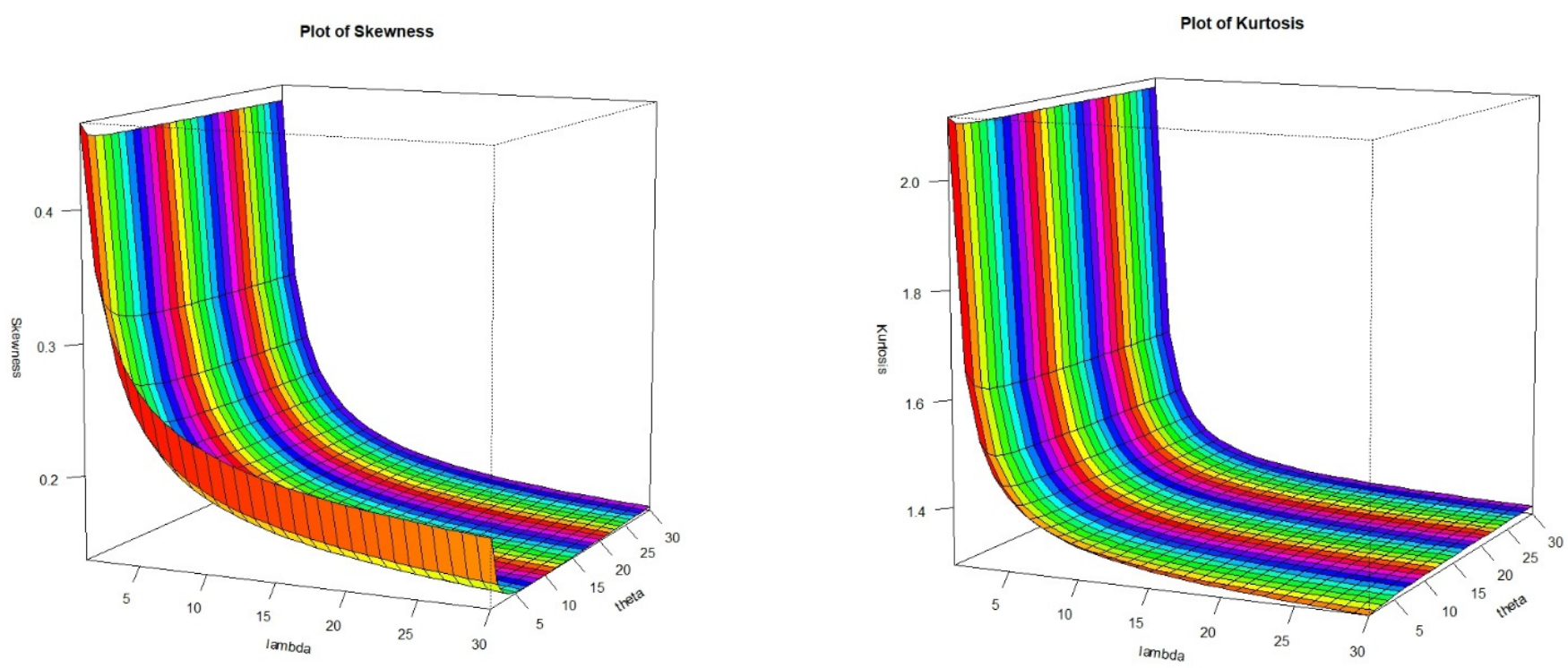

Figure 3. 3D plots of Bo and Mo.

Bowley's skewness was plotted for increasing values of $\lambda$ and $\theta$. From the plot of the skewness, it is clear that the distribution was positively skewed, and the skewness increased with the decrease in $\theta$ and increase in $\lambda$ and vice versa.

Moor's kurtosis was plotted for increasing values of $\lambda$ and $\theta$. From the plot, it is clear that the kurtosis of the distribution increased with the increase in $\lambda$ and $\theta$.

\subsection{Moments and Related Measures}

If $X$ has the PDF given by Equation (12), then its $n$th moment can be calculated as

$$
\mu_{n}^{\prime}=\sum_{i, d=0}^{\infty} W_{i, d} \int_{0}^{\infty} 2 \theta(d+1) x^{n+1}(1+x)^{-2 \theta(d+1)-1}(1+2 x)^{\theta(d+1)-1} \mathrm{~d} x .
$$

Using the binomial expansion, the $n$th moment of the HLITL distribution can be obtained as follows:

$$
\begin{gathered}
\mu_{n}^{\prime}=\sum_{i, d, k=0}^{\infty} W_{i, d} 2 \theta(d+1)\left(\begin{array}{c}
\theta(d+1)-1 \\
k
\end{array}\right) \int_{0}^{\infty} x^{k+n+1}(1+x)^{-\theta(d+1)-k-2} \mathrm{~d} x \\
=\sum_{i, d, k=0}^{\infty} \psi_{i, d, k} B(k+n+2, \theta(d+1)-n),
\end{gathered}
$$

where $\psi_{i, d, k}=2 \theta(d+1)\left(\begin{array}{c}\theta(d+1)-1 \\ k\end{array}\right) W_{i, d}$. 
Further, the $n$th central moment of $X$ is defined as

$$
\mu_{n}=E\left(X-\mu_{1}^{\prime}\right)^{n}=\sum_{i=0}^{n}(-1)^{i}\left(\begin{array}{c}
n \\
i
\end{array}\right)\left(\mu_{1}^{\prime}\right)^{i} \mu_{n-i}^{\prime} .
$$

The numerical values for specific values of the parameters of the first four ordinary moments $\mu_{1}^{\prime}, \mu_{2}^{\prime}{ }_{2}, \mu^{\prime}{ }_{3}$, and $\mu^{\prime}{ }_{4}$, the variance $\left(\sigma^{2}\right)$, the coefficient of variation $\left(\mathrm{CV}=\frac{\sigma}{\mu_{1}^{\prime}}\right)$, the coefficient of skewness $\left(\mathrm{SK}=\frac{\mu_{3}}{\left(\mu_{2}\right)^{1.5}}\right)$, and the coefficient of kurtosis $\left(\mathrm{KU}=\frac{\mu_{4}}{\left(\mu_{2}\right)^{2}}\right)$ of the HLITL distribution are listed in Tables 2 and 3.

Table 2. Some moments of the HLITL distribution.

\begin{tabular}{ccccccc}
\hline$\mu^{\prime}{ }_{r}$ & $\begin{array}{c}\theta=5.0, \\
\lambda=0.5\end{array}$ & $\begin{array}{c}\theta=5.0, \\
\lambda=1.0\end{array}$ & $\begin{array}{c}\theta=5.0, \\
\lambda=1.5\end{array}$ & $\begin{array}{c}\theta=5.0, \\
\lambda=2.0\end{array}$ & $\begin{array}{c}\theta=5.0, \\
\lambda=2.5\end{array}$ & $\begin{array}{c}\theta=5.0, \\
\lambda=3.0\end{array}$ \\
\hline$\mu^{\prime}{ }_{1}$ & 0.334 & 0.555 & 0.716 & 0.844 & 0.951 & 1.044 \\
\hline$\mu^{\prime}{ }_{2}$ & 0.336 & 0.646 & 0.928 & 1.188 & 1.431 & 1.659 \\
\hline$\mu^{\prime}{ }_{3}$ & 0.804 & 1.597 & 2.376 & 3.14 & 3.889 & 4.626 \\
\hline$\mu^{\prime}{ }_{4}$ & 5.137 & 10.268 & 15.389 & 20.498 & 25.594 & 30.677 \\
\hline$\sigma^{2}$ & 0.225 & 0.338 & 0.415 & 0.475 & 0.526 & 0.569 \\
\hline $\mathrm{SK}$ & 5.079 & 4.398 & 4.176 & 4.071 & 4.011 & 3.973 \\
\hline $\mathrm{KU}$ & 84.146 & 66.827 & 61.804 & 59.545 & 58.306 & 57.546 \\
\hline $\mathrm{CV}$ & 1.418 & 1.048 & 0.9 & 0.816 & 0.762 & 0.723 \\
\hline
\end{tabular}

Table 3. Some moments of the HLITL distribution.

\begin{tabular}{ccccccc}
\hline$\mu^{\prime}{ }_{r}$ & $\begin{array}{c}\theta=8.0, \\
\lambda=0.5\end{array}$ & $\begin{array}{c}\theta=8.0, \\
\lambda=1.0\end{array}$ & $\begin{array}{c}\theta=8.0, \\
\lambda=1.5\end{array}$ & $\begin{array}{c}\theta=8.0, \\
\lambda=2.0\end{array}$ & $\begin{array}{c}\theta=8.0, \\
\lambda=2.5\end{array}$ & $\begin{array}{c}\theta=8.0, \\
\lambda=3.0\end{array}$ \\
\hline$\mu^{\prime}{ }_{1}$ & 0.233 & 0.381 & 0.484 & 0.565 & 0.63 & 0.686 \\
\hline$\mu^{\prime}{ }_{2}$ & 0.137 & 0.259 & 0.367 & 0.464 & 0.552 & 0.633 \\
\hline$\mu^{\prime}{ }_{3}$ & 0.148 & 0.291 & 0.43 & 0.563 & 0.692 & 0.816 \\
\hline$\mu^{\prime}{ }_{4}$ & 0.261 & 0.521 & 0.779 & 1.034 & 1.286 & 1.535 \\
\hline$\sigma^{2}$ & 0.083 & 0.114 & 0.132 & 0.145 & 0.155 & 0.162 \\
\hline $\mathrm{SK}$ & 3.249 & 2.732 & 2.566 & 2.489 & 2.447 & 2.421 \\
\hline $\mathrm{KU}$ & 23.342 & 18.335 & 16.955 & 16.367 & 16.065 & 15.891 \\
\hline $\mathrm{CV}$ & 1.232 & 0.889 & 0.751 & 0.674 & 0.624 & 0.587 \\
\hline
\end{tabular}

As shown in Tables 2 and 3 , for the same value of $\theta$ and for the increasing value of $\lambda$, the values of the moments increased, but the values of $\mathrm{SK}, \mathrm{KU}$, and $\mathrm{CV}$ decreased. At the same value of $\lambda$, the moment values increased with the value of $\theta$, while the values of SK, $\mathrm{KU}$, and $\mathrm{CV}$ decreased. As the value of $\theta$ increased, all measures decreased with the value of $\lambda$. Thus, the HLITL distribution was positively skewed and leptokurtic.

\subsection{Bonferroni and Lorenz Curves}

Bonferroni and Lorenz curves have been applied to several fields, such as economics and engineering, and they are respectively defined by 


$$
\begin{gathered}
L_{o}(x)=(E(X))^{-1} \int_{0}^{x} y f(y ; \lambda, \theta) d y, \\
B_{e}(x)=(F(x ; \lambda, \theta))^{-1} L_{o}(x),
\end{gathered}
$$

where $\int_{0}^{x} y f(y ; \lambda, \theta) d y$, denotes the lower incomplete moment. For the HLITL distribution, the Bonferroni and Lorenz curves are respectively defined as follows:

$$
\begin{gathered}
L_{0}(x)=\frac{\sum_{i, d, k=0}^{\infty} \psi_{i, d, k} B(k+3, \theta(d+1)-1, x /(1+x))}{\sum_{i, d, k=0}^{\infty} \psi_{i, d, k} B(k+3, \theta(d+1)-1)}, \\
B_{e}(x)=\frac{\left\{1+[1-H]^{\lambda}\right\}}{2[1-H]^{\lambda}}\left[\frac{\sum_{i, d, k=0}^{\infty} \psi_{i, d, k} B(k+3, \theta(d+1)-1, x /(1+x))}{\sum_{i, d, k=0}^{\infty} \psi_{i, d, k} B(k+3, \theta(d+1)-1)}\right],
\end{gathered}
$$

where $\psi_{i, d, k}$ is defined above and $B(., ., x /(1+x))$ represents an incomplete beta function.

\section{Parameters Estimation}

In this section, the estimation of $\lambda$ and $\theta$ of the HLITL distribution under the SRS and RSS are discussed. Additionally, we examine the behavior of the estimates, namely in the simulation study.

\subsection{Parameter Estimation under SRS}

In this section, the HLITL parameters are estimated by the ML method. Let $X_{1}, X_{2}, \ldots, X_{n}$ be SRS obeying the HLITL distribution with observed values $x_{1}, x_{2}, \ldots, x_{n}$, respectively. The log-likelihood function of the HLITL distribution, denoted by $\ln \ell$, is obtained as follows:

$$
\begin{gathered}
\ln \ell=n \ln 4 \lambda+n \ln \theta+\sum_{i=1}^{n} \ln x_{i}-(2 \theta+1) \sum_{i=1}^{n} \ln \left(1+x_{i}\right)+(\theta-1) \sum_{i=1}^{n} \ln \left(1+2 x_{i}\right) \\
+(\lambda-1) \sum_{i=1}^{n} \ln \left[1-H_{i}\right]-2 \sum_{i=1}^{n} \ln \left[1+\left[1-H_{i}\right]^{\lambda}\right],
\end{gathered}
$$

where $H_{i}=\left(1+2 x_{i}\right)^{\theta}\left(1+x_{i}\right)^{-2 \theta}$. The partial derivatives of the log-likelihood function associated with $\lambda$ and $\theta$ are respectively given by

$$
\begin{gathered}
\frac{\partial \ln \ell}{\partial \lambda}=\frac{n}{\lambda}+\sum_{i=1}^{n} \ln \left[1-H_{i}\right]-2 \sum_{i=1}^{n} \ln \left[1-H_{i}\right]\left\{\left[1-H_{i}\right]^{-\lambda}+1\right\}^{-1}, \\
\frac{\partial \ln \ell}{\partial \theta}=\frac{n}{\theta}-2 \sum_{i=1}^{n} \ln \left[1+x_{i}\right]+\sum_{i=1}^{n} \ln \left[1+2 x_{i}\right]-(\lambda-1) \sum_{i=1}^{n} h_{i}\left(1-H_{i}\right)^{-1}+\sum_{i=1}^{n} \frac{2 \lambda h_{i}\left[1-H_{i}\right]^{\lambda-1}}{1+\left[1-H_{i}\right]^{\lambda}} \\
\text { where } h_{i}=\left(\left(1+2 x_{i}\right)\left(1+x_{i}\right)^{-2}\right)^{\theta} \ln \left(\left(1+2 x_{i}\right)\left(1+x_{i}\right)^{-2}\right) .
\end{gathered}
$$

By solving the nonlinear equations $\partial \ln \ell / \partial \lambda=0$ and $\partial \ln \ell / \partial \theta=0$ with respect to $\lambda$ and $\theta$, the ML estimators could be obtained. 


\subsection{Estimation under RSS}

Suppose that $X_{(i) i c}, i=1,2, \ldots, m, c=1,2, \ldots, k$ denotes a selected RSS from the HLITL distribution, where the sample size is $n=m k, m$ denotes the set size, and $k$ is the number of cycles. For simplicity, assume that $Y_{i c}=X_{(i) i c}$. Then, the fixed $c, Y_{i c}$ is independent and has a PDF equal to the PDF of the $i$ th order statistics. The likelihood function $L_{R}$ of the RSS of samples $y_{1 c}, y_{2 c}, \ldots, y_{m c}$ can be expressed as

$$
\begin{aligned}
& L_{R}= \prod_{c=1}^{k} \prod_{i=1}^{m}\left(\begin{array}{c}
m \\
i
\end{array}\right)\left[F\left(y_{i c} ; \lambda, \theta\right)\right]^{i-1} f\left(y_{i c} ; \lambda, \theta\right)\left[1-F\left(y_{i c} ; \lambda, \theta\right)\right]^{m-i} \\
& L_{R}=\prod_{c=1}^{k} \prod_{i=1}^{m}\left(\begin{array}{c}
m \\
i
\end{array}\right)\left[\frac{2\left[1-H_{i c}\right]^{\lambda}}{1+\left[1-H_{i c}\right]^{\lambda}}\right]^{i-1} \frac{4 \lambda \theta y_{i c}\left(1+y_{i c}\right)^{-2 \theta-1}\left(1+2 y_{i c}\right)^{\theta-1}\left[1-H_{i c}\right]^{\lambda-1}}{\left[1+\left[1-H_{i c}\right]^{\lambda}\right]^{2}} \\
& {\left[\frac{1-\left[1-H_{i c}\right]^{\lambda}}{1+\left[1-H_{i c}\right]^{\lambda}}\right]^{m-i}, }
\end{aligned}
$$

where $H_{i c}=\frac{\left(1+2 y_{i c}\right)^{\theta}}{\left(1+y_{i c}\right)^{2 \theta}}$. The log-likelihood function of the HLITL distribution is given by

$$
\begin{gathered}
\ln L_{R}=C+m k \ln 4 \lambda+m k \ln \theta+\sum_{c=1}^{k} \sum_{i=1}^{m}(i-1) \ln \left[\frac{2\left[1-H_{i c}\right]^{\lambda}}{1+\left[1-H_{i c}\right]^{\lambda}}\right]+\sum_{c=1}^{k} \sum_{i=1}^{m} \ln \left[y_{i c}\right] \\
-(2 \theta+1) \sum_{c=1}^{k} \sum_{i=1}^{m} \ln \left[1+y_{i c}\right]+(\theta-1) \sum_{c=1}^{k} \sum_{i=1}^{m} \ln \left[1+2 y_{i c}\right] \\
+(\lambda-1) \sum_{c=1}^{k} \sum_{i=1}^{m} \ln \left[1-H_{i c}\right]-2 \sum_{c=1}^{k} \sum_{i=1}^{m} \ln \left[1+\left[1-H_{i c}\right]^{\lambda}\right]+\sum_{i=1}^{m}(m-i) \ln \left[\frac{1-\left[1-H_{i c}\right]^{\lambda}}{1+\left[1-H_{i c}\right]^{\lambda}}\right],
\end{gathered}
$$

where $C=\sum_{c=1}^{k} \sum_{i=1}^{m} \ln \left[\left(\begin{array}{c}m \\ i\end{array}\right)\right]$. The partial derivatives of $\ln L_{R}$ associated with unknown parameters are expressed as follows:

$$
\begin{aligned}
& \frac{\partial \ln L_{R}}{\partial \lambda}=\frac{m k}{\lambda}-\sum_{c=1}^{k} \sum_{i=1}^{m} \frac{(i-1) \ln \left[1-H_{i c}\right]}{1+\left[1-H_{i c}\right]^{\lambda}}+\sum_{c=1}^{k} \sum_{i=1}^{m} i \ln \left[1-H_{i c}\right]-2 \sum_{c=1}^{k} \sum_{i=1}^{m} \frac{\ln \left[1-H_{i c}\right]\left[1-H_{i c}\right]^{\lambda}}{1+\left[1-H_{i c}\right]^{\lambda}} \\
& -2 \sum_{c=1}^{k} \sum_{i=1}^{m} \frac{(m-i) \ln \left[1-H_{i c}\right]\left(1-H_{i c}\right)^{\lambda}}{1-\left(1-H_{i c}\right)^{2 \lambda}} \\
& \frac{\partial \ln L_{R}}{\partial \theta}=\frac{m k}{\theta}+\sum_{c=1}^{k} \sum_{i=1}^{m} \frac{(i-1) \lambda\left(1-H_{i c}\right)^{\lambda-1} h_{i c}}{\left(1+\left(1-H_{i c}\right)^{\lambda}\right)}-2 \sum_{c=1}^{k} \sum_{i=1}^{m} \ln \left[1+y_{i c}\right]-\sum_{c=1}^{k} \sum_{i=1}^{m} \frac{(\lambda i-1) h_{i c}}{1-H_{i c}} \\
& +\sum_{c=1}^{k} \sum_{i=1}^{m} \ln \left[1+2 y_{i c}\right]+2 \sum_{c=1}^{k} \sum_{i=1}^{m} \frac{\lambda\left(1-H_{i c}\right)^{\lambda-1} h_{i c}}{1+\left(1-H_{i c}\right)^{\lambda}}+2 \lambda \sum_{c=1}^{k} \sum_{i=1}^{m} \frac{(m-i) h_{i c}\left(1-H_{i c}\right)^{\lambda-1}}{1-\left(1-H_{i c}\right)^{2 \lambda}}
\end{aligned}
$$

where $h_{i c}=\left(\frac{1+2 y_{i c}}{\left(1+y_{i c}\right)^{2}}\right)^{\theta} \ln \left(\frac{1+2 y_{i c}}{\left(1+y_{i c}\right)^{2}}\right)$. In solving the nonlinear equations $\partial \ln L_{R} / \partial \lambda=0$ and $\partial \ln L_{R} / \partial \theta=0$ with respect to $\lambda$ and $\theta$ numerically, the ML estimators can be obtained.

\subsection{Simulation Procedures}

This section presents the numerical method to obtain the ML estimates (MLEs) of $\lambda$ and $\theta$ for the HLITL distribution under the RSS and SRS. A comparison study was conducted based on the mean square error (MSE) value, biases, and relative efficiency (RE). The following algorithm was performed using MATHEMATICA software [31] to obtain the MLEs and the suggested criteria measures.

Step 1: A random sample of size $n=30,50,100,200$, or 300 with a set size of $m$ and number of cycles $k$ where $n=m k$ is generated from the HLITL distribution.

Step 2: The chosen values of the parameters are as follows: $(\lambda=2, \theta=5),(\lambda=3$, $\theta=5),(\lambda=1, \theta=8),(\lambda=2, \theta=8)$, and $(\lambda=3, \theta=8)$. 
Step 3: For each $n$ and specified parameter value, the MLE values under SRS and RSS are obtained.

Step 4: Repeat steps 1-3 N = 2000 times. Then, the bias, MSE, and RE values, where RE $=$ MSE (SRS) $/$ MSE (RSS), are computed.

Step 5: The outcomes of this study are given in Tables 4-8.

Table 4. MLE, bias, MSE, and RE of the HLITL distribution under SRS and RSS for $\lambda=2, \theta=5$.

\begin{tabular}{|c|c|c|c|c|c|c|c|c|}
\hline \multirow{2}{*}{$n$} & \multirow{2}{*}{ Parameters } & \multicolumn{3}{|c|}{ SRS } & \multicolumn{3}{|c|}{ RSS } & \multirow{2}{*}{ RE } \\
\hline & & MLE & Bias & MSE & MLE & Bias & MSE & \\
\hline \multirow{2}{*}{30} & $\lambda$ & 2.24665 & 0.24665 & 0.44814 & 2.05599 & 0.05599 & 0.07258 & 6.17398 \\
\hline & $\theta$ & 5.42395 & 0.42395 & 2.15164 & 5.09999 & 0.09999 & 0.40560 & 5.30488 \\
\hline \multirow{2}{*}{50} & $\lambda$ & 2.13933 & 0.13933 & 0.18853 & 2.02705 & 0.02705 & 0.02444 & 7.71307 \\
\hline & $\theta$ & 5.24674 & 0.24674 & 0.96227 & 5.05890 & 0.05890 & 0.12829 & 7.50083 \\
\hline \multirow{2}{*}{100} & $\lambda$ & 2.02133 & 0.02133 & 0.06865 & 2.01428 & 0.01428 & 0.00672 & 10.21169 \\
\hline & $\theta$ & 5.12873 & 0.12873 & 0.42011 & 5.02657 & 0.02657 & 0.03839 & 10.94189 \\
\hline \multirow[b]{2}{*}{200} & $\lambda$ & 1.98450 & -0.01550 & 0.04086 & 1.99913 & -0.00087 & 0.00271 & 15.06497 \\
\hline & $\theta$ & 4.96450 & -0.03550 & 0.19184 & 4.98999 & -0.01001 & 0.01459 & 13.14884 \\
\hline \multirow{2}{*}{300} & $\lambda$ & 2.00841 & 0.00841 & 0.02286 & 1.99921 & -0.00079 & 0.00099 & 23.08329 \\
\hline & $\theta$ & 5.01792 & 0.01792 & 0.14397 & 4.99748 & -0.00252 & 0.00564 & 25.50732 \\
\hline
\end{tabular}

Table 5. MLE, bias, MSE, and RE of the HLITL distribution under SRS and RSS for $\lambda=3, \theta=5$.

\begin{tabular}{|c|c|c|c|c|c|c|c|c|}
\hline \multirow{2}{*}{$n$} & \multirow{2}{*}{ Parameters } & \multicolumn{3}{|c|}{ SRS } & \multicolumn{3}{|c|}{ RSS } & \multirow{2}{*}{ RE } \\
\hline & & MLE & Bias & MSE & MLE & Bias & MSE & \\
\hline \multirow{2}{*}{30} & $\lambda$ & 3.49833 & 0.49833 & 1.51722 & 3.06551 & 0.06551 & 0.18998 & 7.98617 \\
\hline & $\theta$ & 5.54666 & 0.54666 & 1.87525 & 5.08473 & 0.08473 & 0.27925 & 6.71538 \\
\hline \multirow{2}{*}{50} & $\lambda$ & 3.17527 & 0.17527 & 0.39593 & 3.01343 & 0.01343 & 0.05829 & 6.79289 \\
\hline & $\theta$ & 5.23404 & 0.23404 & 0.74310 & 5.01014 & 0.01014 & 0.11053 & 6.72327 \\
\hline \multirow{2}{*}{100} & $\lambda$ & 3.06525 & 0.06525 & 0.22305 & 3.01564 & 0.01564 & 0.02158 & 10.33606 \\
\hline & $\theta$ & 5.10540 & 0.10540 & 0.36652 & 5.01876 & 0.01876 & 0.03375 & 10.85922 \\
\hline \multirow[b]{2}{*}{200} & $\lambda$ & 3.06158 & 0.06158 & 0.12887 & 3.01063 & 0.01063 & 0.00599 & 21.49613 \\
\hline & $\theta$ & 5.05276 & 0.05276 & 0.20716 & 5.01286 & 0.01286 & 0.00901 & 22.98753 \\
\hline \multirow{2}{*}{300} & $\lambda$ & 3.04510 & 0.04510 & 0.07566 & 3.00965 & 0.00965 & 0.00249 & 30.38488 \\
\hline & $\theta$ & 5.00445 & 0.00445 & 0.11340 & 5.01317 & 0.01317 & 0.00432 & 26.24375 \\
\hline
\end{tabular}

Table 6. MLE, bias, MSE, and RE of the HLITL distribution under SRS and RSS for $\lambda=1, \theta=8$.

\begin{tabular}{|c|c|c|c|c|c|c|c|c|}
\hline \multirow{2}{*}{$n$} & \multirow{2}{*}{ Parameters } & \multicolumn{3}{|c|}{ SRS } & \multicolumn{3}{|c|}{ RSS } & \multirow{2}{*}{ RE } \\
\hline & & MLE & Bias & MSE & MLE & Bias & MSE & \\
\hline \multirow[b]{2}{*}{30} & $\lambda$ & 1.07235 & 0.07235 & 0.07101 & 1.01680 & 0.01680 & 0.01125 & 6.31288 \\
\hline & $\theta$ & 8.76351 & 0.76351 & 7.54481 & 8.27698 & 0.27698 & 1.62355 & 4.64711 \\
\hline \multirow{2}{*}{50} & $\lambda$ & 1.05411 & 0.05411 & 0.04031 & 1.00142 & 0.00142 & 0.00504 & 7.99685 \\
\hline & $\theta$ & 8.61090 & 0.61090 & 4.96154 & 8.09470 & 0.09470 & 0.67902 & 7.30688 \\
\hline \multirow{2}{*}{100} & $\lambda$ & 1.02216 & 0.02216 & 0.01626 & 0.99950 & -0.00050 & 0.00107 & 15.16481 \\
\hline & $\theta$ & 8.36669 & 0.36669 & 2.78284 & 7.99541 & -0.00459 & 0.15104 & 18.42416 \\
\hline \multirow{2}{*}{200} & $\lambda$ & 1.01110 & 0.01110 & 0.00669 & 1.00159 & 0.00159 & 0.00031 & 21.29228 \\
\hline & $\theta$ & 8.15951 & 0.15951 & 0.98182 & 8.02785 & 0.02785 & 0.04678 & 20.98708 \\
\hline \multirow{2}{*}{300} & $\lambda$ & 0.99242 & -0.00758 & 0.00389 & 0.99977 & -0.00023 & 0.00017 & 23.37761 \\
\hline & $\theta$ & 7.99837 & -0.00163 & 0.52617 & 8.00809 & 0.00809 & 0.02578 & 20.41341 \\
\hline
\end{tabular}


Table 7. MLE, bias, MSE, and RE of the HLITL distribution under SRS and RSS for $\lambda=2, \theta=8$.

\begin{tabular}{|c|c|c|c|c|c|c|c|c|}
\hline \multirow{2}{*}{$n$} & \multirow{2}{*}{ Parameters } & \multicolumn{3}{|c|}{ SRS } & \multicolumn{3}{|c|}{ RSS } & \multirow{2}{*}{ RE } \\
\hline & & MLE & Bias & MSE & MLE & Bias & MSE & \\
\hline \multirow[b]{2}{*}{30} & $\lambda$ & 2.11451 & 0.11451 & 0.23930 & 2.04546 & 0.04546 & 0.08626 & 2.77425 \\
\hline & $\theta$ & 8.14470 & 0.14470 & 2.72208 & 8.13691 & 0.13691 & 0.95506 & 2.85016 \\
\hline \multirow{2}{*}{50} & $\lambda$ & 2.10872 & 0.10872 & 0.17984 & 2.01079 & 0.01079 & 0.02425 & 7.41578 \\
\hline & $\theta$ & 8.30965 & 0.30965 & 2.20228 & 8.01382 & 0.01382 & 0.32892 & 6.69551 \\
\hline \multirow{2}{*}{100} & $\lambda$ & 2.07331 & 0.07331 & 0.08344 & 2.01130 & 0.01130 & 0.00753 & 11.07905 \\
\hline & $\theta$ & 8.10855 & 0.10855 & 1.24516 & 8.04232 & 0.04232 & 0.10381 & 11.99414 \\
\hline \multirow{2}{*}{200} & $\lambda$ & 2.00342 & 0.00342 & 0.03284 & 1.99796 & -0.00204 & 0.00277 & 11.84549 \\
\hline & $\theta$ & 7.95718 & -0.04282 & 0.46577 & 7.99595 & -0.00405 & 0.03844 & 12.11569 \\
\hline \multirow[b]{2}{*}{300} & $\lambda$ & 2.02033 & 0.02033 & 0.02537 & 1.99699 & -0.00301 & 0.00103 & 24.59269 \\
\hline & $\theta$ & 8.09456 & 0.09456 & 0.38287 & 7.98655 & -0.01345 & 0.01498 & 25.55199 \\
\hline
\end{tabular}

Table 8. MLE, bias, MSE, and RE of the HLITL distribution under SRS and RSS for $\lambda=3, \theta=8$.

\begin{tabular}{|c|c|c|c|c|c|c|c|c|}
\hline \multirow{2}{*}{$n$} & \multirow{2}{*}{ Parameters } & \multicolumn{3}{|c|}{ SRS } & \multicolumn{3}{|c|}{ RSS } & \multirow{2}{*}{ RE } \\
\hline & & MLE & Bias & MSE & MLE & Bias & MSE & \\
\hline \multirow{2}{*}{30} & $\lambda$ & 3.41418 & 0.41418 & 1.27229 & 3.09333 & 0.09333 & 0.15659 & 8.12492 \\
\hline & $\theta$ & 8.55175 & 0.55175 & 4.23735 & 8.20260 & 0.20260 & 0.50519 & 8.38760 \\
\hline \multirow{2}{*}{50} & $\lambda$ & 3.22376 & 0.22376 & 0.58594 & 2.99541 & -0.00459 & 0.06124 & 9.56734 \\
\hline & $\theta$ & 8.39282 & 0.39282 & 1.95568 & 7.99319 & -0.00681 & 0.25080 & 7.79780 \\
\hline \multirow{2}{*}{100} & $\lambda$ & 3.12361 & 0.12361 & 0.21725 & 3.01169 & 0.01169 & 0.02121 & 10.24074 \\
\hline & $\theta$ & 8.19048 & 0.19048 & 1.01699 & 8.03179 & 0.03179 & 0.08586 & 11.84500 \\
\hline \multirow[b]{2}{*}{200} & $\lambda$ & 3.04516 & 0.04516 & 0.11087 & 3.00666 & 0.00666 & 0.00635 & 17.44767 \\
\hline & $\theta$ & 8.05130 & 0.05130 & 0.40836 & 8.00759 & 0.00759 & 0.02846 & 14.35016 \\
\hline \multirow{2}{*}{300} & $\lambda$ & 3.04564 & 0.04564 & 0.07322 & 3.00014 & 0.00014 & 0.00382 & 19.15888 \\
\hline & $\theta$ & 8.08202 & 0.08202 & 0.30526 & 8.00310 & 0.00310 & 0.01608 & 18.98614 \\
\hline
\end{tabular}

Based on the numerical study, the following conclusions can be drawn.

As presented in Tables 4 and 8 , for a fixed value of $\theta$, the MSE of the estimates of $\lambda$ increased with the value of $\lambda$, while the MSE of the estimates of $\theta$ decreased under SRS and RSS with $n$. Furthermore, the MSE values of the estimates of $\lambda$ were smaller than those of the estimates of $\theta$ for all values of $n$ under both sampling schemes.

As $\lambda$ increased from two to three and $\theta$ increased from five to eight, the MSE values of both estimates increased under both schemes. In addition, the MSE values of the estimates of $\theta$ were smaller than those of the estimates of $\lambda$ for all sample sizes, as shown in Tables 4 and 8.

When the value of $\lambda$ increased and the value of $\theta$ decreased, the MSE values of the estimates of $\lambda$ increased, while the MSE values of the estimates of $\theta$ decreased under both sampling schemes (see Tables 4 and 6).

Generally, the MLE values of the HLITL distribution under RSS were smaller than those under the SRS. Additionally, when the MSE values of both estimates decreased, the RE increased. When $n$ increased, the RE values increased, and the MSE values decreased.

\section{Applications to Real Data}

The experiments on two real datasets were conducted to assess the flexibility of the proposed HLITL model. The first dataset included the relief times of 20 patients receiving an analgesic [32]. The second dataset was taken from [33], which included the failure times of the air conditioning system of an airplane. The HLITL model was compared with four competing models: AP exponential (APE) [34], alpha power (AP) Lindley (APL) [35], Fréchet inverse exponential (OFIE) [36], and odd Fréchet inverse Rayleigh (OFIR) [37]. Some descriptive statistics of the two datasets are given in Table 9, and the boxplot is shown in Figure 4. 
Table 9. Descriptive statistics for the datasets.

\begin{tabular}{llllllll}
\hline & $\boldsymbol{n}$ & Min & Max & Mean & Median & SK & KU \\
\hline Data 1 & 20 & 1.1 & 4.1 & 1.9 & 1.7 & 1.862 & 4.185 \\
Data 2 & 30 & 1 & 261 & 59.6 & 22 & 1.784 & 2.569 \\
\hline
\end{tabular}
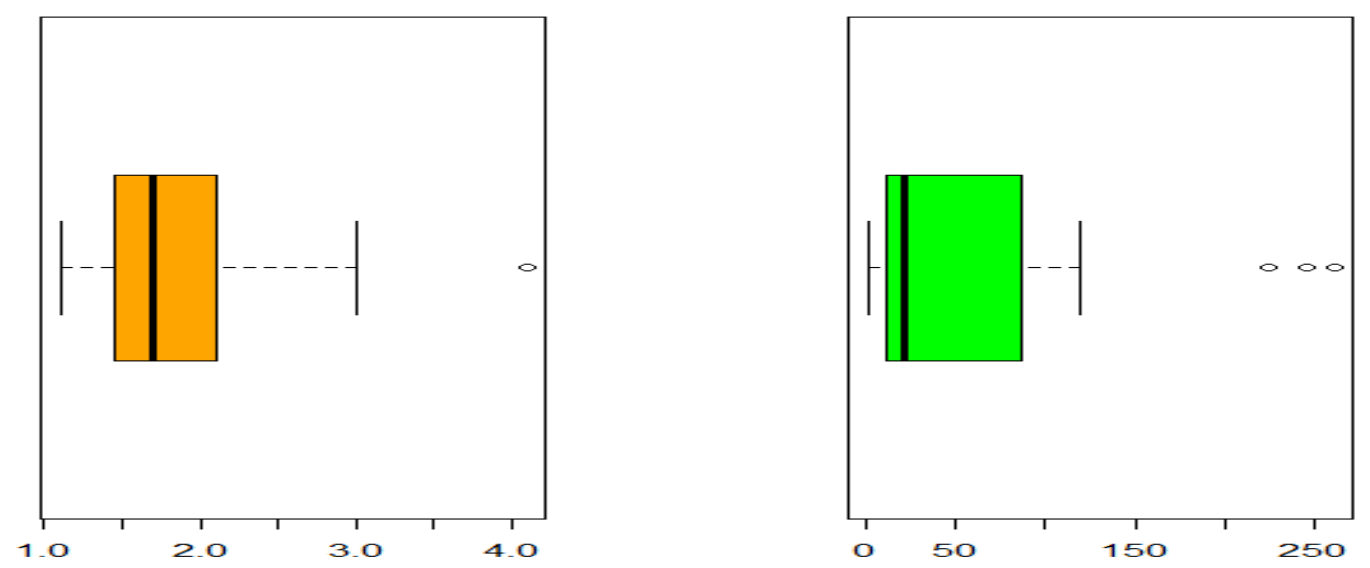

Figure 4. Box plots for both datasets.

The MLEs, along with their standard errors (SEs) of the model parameters, are provided in Tables 10 and 11. Tables 12 and 13 give the values of the Anderson-Darling statistic $\left(\mathrm{A}^{*}\right)$, Cramér-von Mises statistic $\left(\mathrm{W}^{*}\right)$, Akaike information criterion (AIC), corrected AIC (CAIC), Bayesian information criterion (BIC), and Hannan-Quinn information criterion (HQIC).

Table 10. MLEs and their SEs (in parentheses) for the first data set.

\begin{tabular}{lll}
\hline Model & MLE and SE & MLE and SE \\
\hline $\operatorname{HLITL}(\lambda, \theta)$ & $39.964(25.292)$ & $7.027(1.394)$ \\
OFIR $(\alpha, \theta)$ & $1.623(0.182)$ & $1.462(0.265)$ \\
$\operatorname{APL}(\alpha, \gamma)$ & $10540(15462.663)$ & $1.884(0.174)$ \\
$\operatorname{APE}(\alpha, \gamma)$ & $16530(23359.046)$ & $1.488(0.161)$ \\
OFIE $(\alpha, \gamma)$ & $1.073(0.0618)$ & $2.929(0.518)$ \\
\hline
\end{tabular}

Table 11. MLEs and their SEs (in parentheses) for the second dataset.

\begin{tabular}{lll}
\hline Model & MLE and SE & MLE and SE \\
\hline HLITL $(\lambda, \theta)$ & $4.519(1.2539)$ & $0.612(0.115)$ \\
OFIR $(\alpha, \gamma)$ & $6.85(1.761)$ & $0.229(0.034)$ \\
$\operatorname{APL}(\alpha, \gamma)$ & $0.1(0.104)$ & $0.024\left(5.127 \times 10^{-3}\right)$ \\
$\operatorname{APE}(\alpha, \gamma)$ & $8.688 \times 10^{-10}\left(5.698 \times 10^{-8}\right)$ & $8.536 \times 10^{-4}\left(2.844 \times 10^{-3}\right)$ \\
OFIE $(\alpha, \gamma)$ & $4.082(0.7770)$ & $0.47(0.069)$ \\
\hline
\end{tabular}

Table 12. Measures of goodness-of-fit statistics for the first dataset.

\begin{tabular}{lllllll}
\hline Model & AIC & CAIC & BIC & HQIC & A $^{*}$ & $\mathbf{W}^{*}$ \\
\hline HLITL & 34.894 & 35.599 & 33.496 & 35.282 & 0.1702 & 0.0308 \\
OFIR & 35.476 & 36.181 & 34.078 & 35.864 & 0.23635 & 0.0399 \\
APL & 74.416 & 75.122 & 73.018 & 74.804 & 0.75697 & 0.09802 \\
APE & 75.411 & 76.117 & 74.013 & 75.8 & 0.94478 & 0.10762 \\
OFIE & 35.078 & 35.784 & 33.68 & 35.467 & 0.19209 & 0.03343 \\
\hline
\end{tabular}


Table 13. Measures of goodness-of-fit statistics for the second dataset.

\begin{tabular}{lllllll}
\hline Model & AIC & CAIC & BIC & HQIC & A $^{*}$ & W $^{*}$ \\
\hline HLITL & 315.459 & 315.904 & 314.414 & 316.356 & 0.8386 & 0.1152 \\
OFIR & 341.187 & 341.893 & 340.141 & 342.083 & 1.53147 & 0.1613 \\
APL & 370.83 & 371.274 & 369.784 & 371.727 & 1.2629 & 0.1778 \\
APE & 358.775 & 359.22 & 357.729 & 359.672 & 1.5844 & 0.1978 \\
OFIE & 332.232 & 332.677 & 331.186 & 333.129 & 1.4387 & 0.1817 \\
\hline
\end{tabular}

The values in Tables 12 and 13 show that the HLITL distribution had the smallest values among all fitted distributions. Consequently, this distribution can be considered more suitable than the others for the considered data. The estimated PDF, CDF, SF, and PP plots of the HLITL model are presented in Figures 5 and 6, where it can be seen that the HLITL model exhibits a close fit to both datasets.
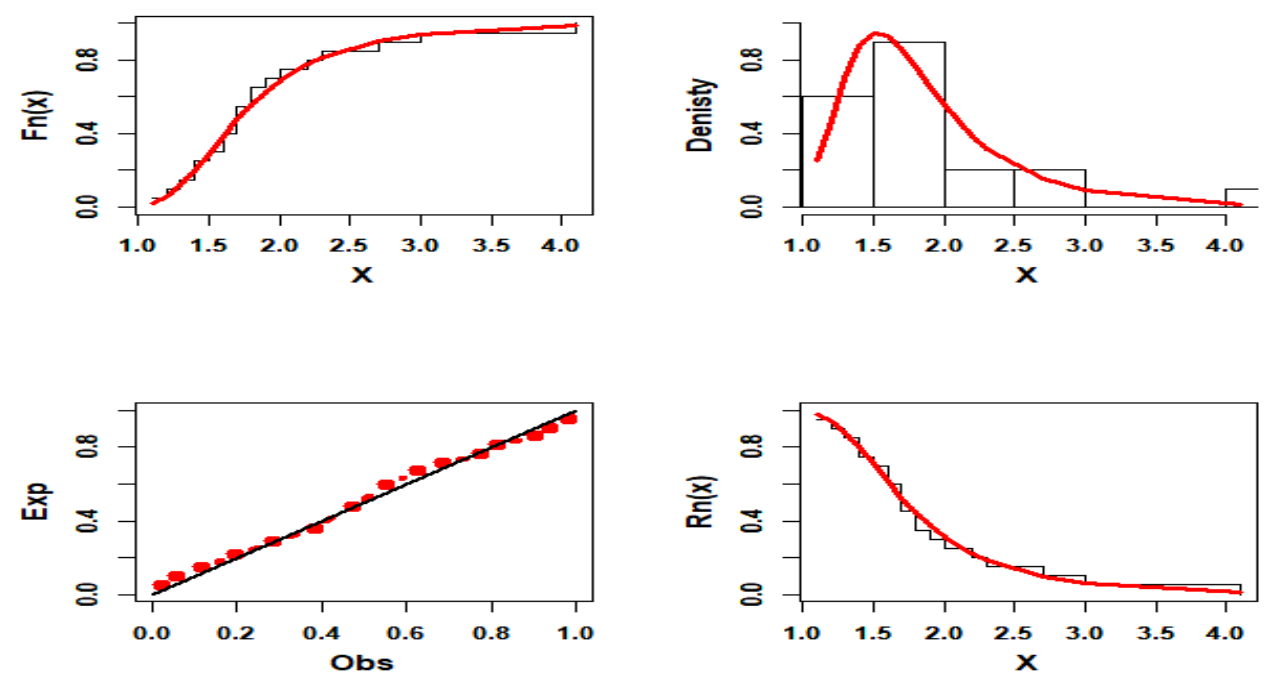

Figure 5. Empirical and estimated CDF, PDF, PP, and SF plots of the HLITL model for the first dataset.
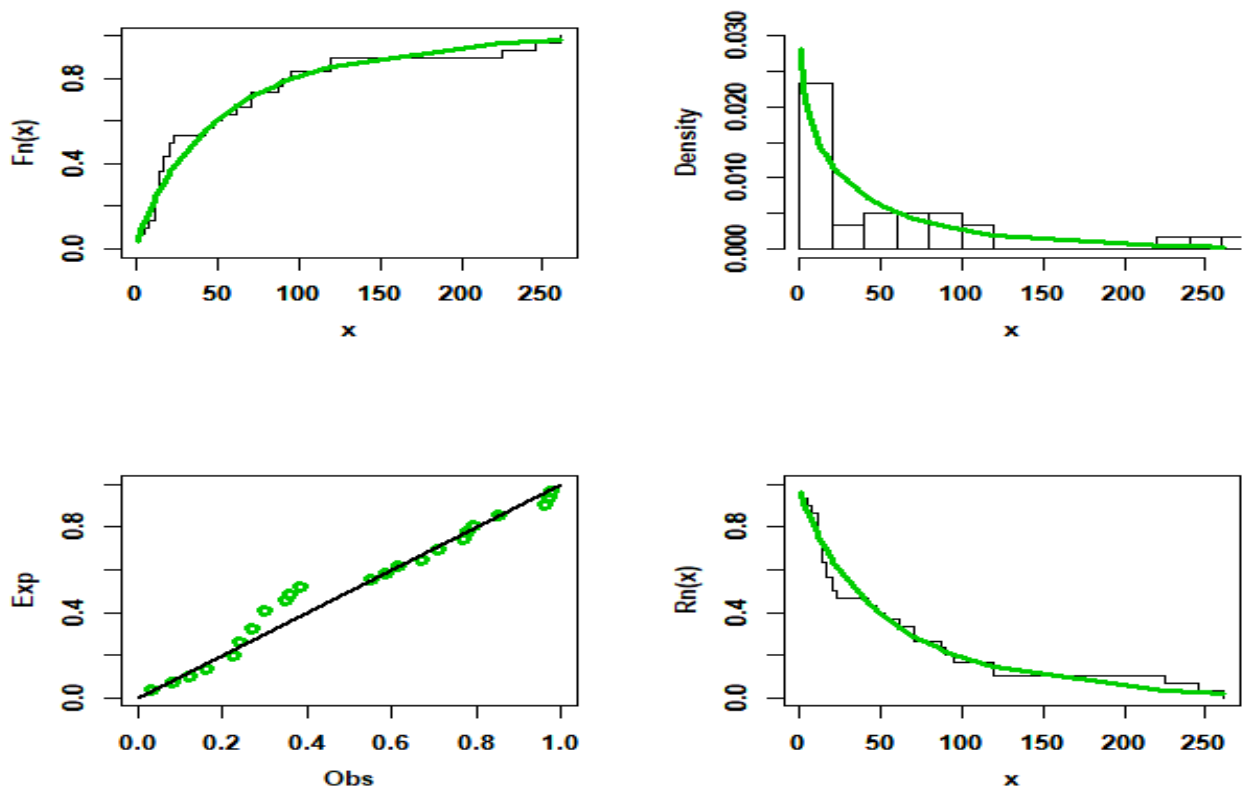

Figure 6. Empirical and estimated CDF, PDF, PP, and SF plots of the HLITL model for the second dataset. 
The author of [38] mentioned that the total time test (TTT) represents a useful graphical approach to confirm whether the data can be applied to a specific distribution or not. The empirical version of the TTT plot is expressed as

$$
T\left(\frac{r}{n}\right)=\frac{\sum_{i=1}^{n}\left[y_{i: n}+(n-r) y_{r: n}\right]}{\sum_{i=1}^{n} y_{i: n}},
$$

where $r=1,2, \ldots, n$ and $y_{i: n}$ denote the $i$ th order statistics of the sample. In [38], it was shown that when the TTT plot represents a straight line, then the HRF is constant, and when the TTT plot is concave (or convex), the HRF increases (or decreases). Additionally, when the TTT plot is first convex and then concave, the HRF is U-shaped (bathtub); otherwise, the HRF is unimodal. The TTT plots presented in Figure 7 show that the estimated HRFs of the first and second datasets increased and decreased. This claim is also confirmed in Figure 8.
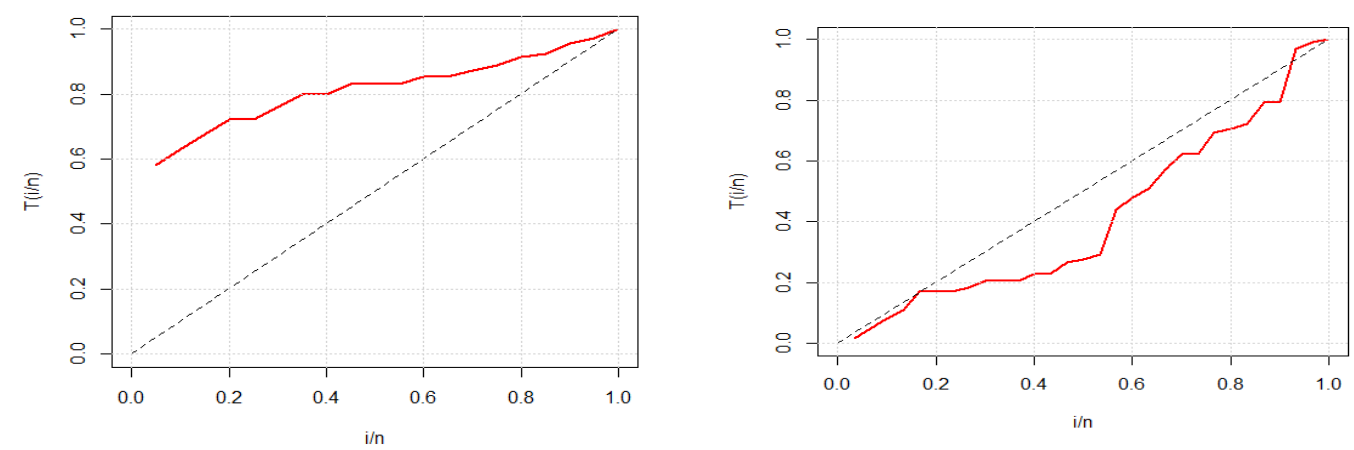

Figure 7. TTT plots for both datasets.
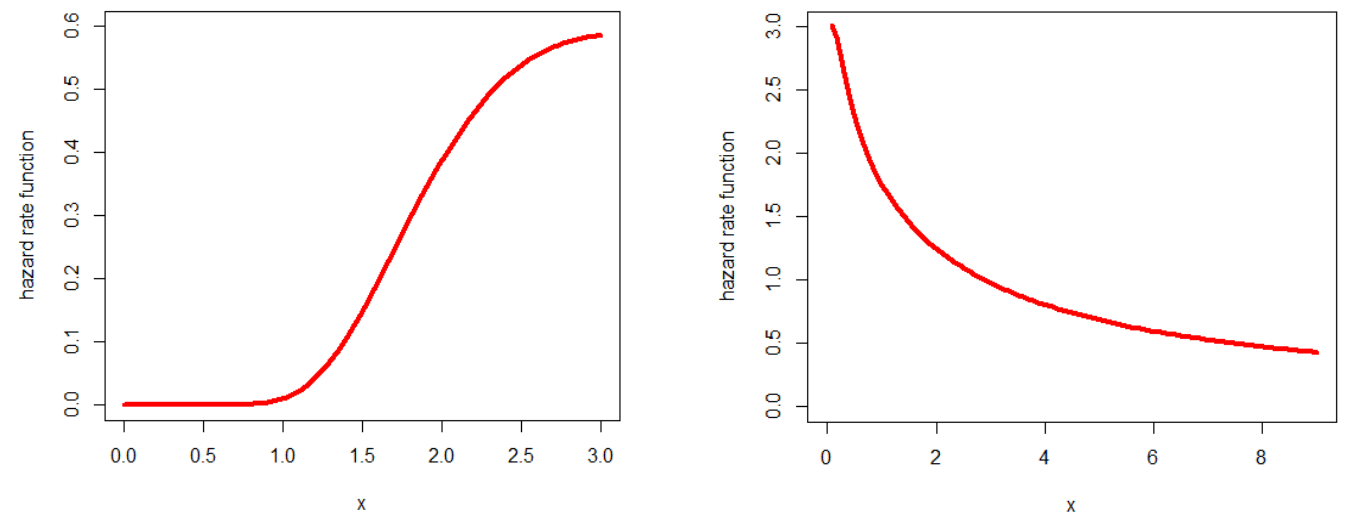

Figure 8. Estimated HRFs of the HLITL model for both datasets.

For both real datasets, the MLE values of both parameters under RSS were obtained. The observed RSS of the first dataset with the set size of four were 1.1, 2.7, 3, and 4.1, and those of the second dataset with the set size of five were 1,5,7,11, and 261. The MLE values of the HLITL distribution for the first dataset and their SE values were $\hat{\lambda}=6.653(5.558)$ and $\hat{\theta}=2.766(1.348)$, and those of the second dataset were $\hat{\lambda}=2.239(1.3448)$ and $\hat{\theta}=0.844(0.071)$.

\section{Conclusions}

This paper proposes an HLITL distribution with two parameters. It is demonstrated that the HLITL distribution can be regarded as a mixture of ITL distributions. Its statistical properties, including the moments, quantile function, skewness, kurtosis, Bonferroni and Lorenz curves, and stochastic ordering, are defined. The maximum likelihood estimators of the HLITL distribution parameters are derived under both SRS and RSS schemes. It was 
shown empirically that the maximum likelihood estimates taken from the observed RSS were more efficient than the corresponding SRS. The merit of the HLITL distribution was evaluated experimentally using two real datasets. The results show that it performed better than the other fitted distributions. Based on the obtained results, the proposed distribution can be useful for modeling data in various fields.

Author Contributions: Conceptualization, F.J.; Data curation, D.S.; Formal analysis, R.B.; Investigation, C.C.; Methodology, M.E. (Mahmoud Elsehetry); Project administration, A.S.H.; Software, M.E. (Mohammed Elgarhy). All authors have read and agreed to the published version of the manuscript.

Funding: This work was funded by the Deanship of Scientific Research (DSR) at King Abdulaziz University, Jeddah, under grant No. FP-188-42.

Institutional Review Board Statement: Not applicable.

Informed Consent Statement: Not applicable.

Data Availability Statement: Datasets are provided in the paper.

Acknowledgments: We would like to thank all four reviewers and the academic editor for their valuable and helpful comments on this manuscript, which greatly improved it in this regard. This project was funded by the Deanship of Scientific Research (DSR) at King Abdulaziz University, Jeddah, under grant No. FP-188-42. The authors, therefore, acknowledge with thanks the DSR's technical and financial support.

Conflicts of Interest: The authors declare no conflict of interest.

\section{References}

1. Nadarajah, S.; Kotz, S. Moments of some J-shaped distributions. J. Appl. Stat. 2003, 30, 311-317. [CrossRef]

2. Ghitany, M.E.; Kotz, S.; Xie, M. On some reliability measures and their stochastic orderings for the Topp-Leone distribution. J. Appl. Stat. 2005, 32, 715-722. [CrossRef]

3. Zghoul, A.A. Record values from a family of J-shaped distributions. Statistica 2011, 71, 355-365.

4. Genc, A.I. Estimation of $\mathrm{P}(\mathrm{X}>\mathrm{Y})$ with Topp-Leone distribution. J. Stat. Comput. Simul. 2013, 83, 326-339. [CrossRef]

5. Keller, A.Z.; Kamath, A.R.R. Alternative reliability models for mechanical systems. In Proceedings of the 3rd International Conference on Reliability and Maintainability, Toulouse, France, 26 February 2015.

6. Sharma, V.K.; Singh, S.K.; Singh, U.; Agiwal, V. The inverse Lindley distribution: A stress-strength reliability model with application to head and neck cancer data. J. Ind. Prod. Eng. 2015, 32, 162-173. [CrossRef]

7. Abd AL-Fattah, A.M.; EL-Helbawy, A.A.; AL-Dayian, G.R. Inverted Kumaraswamy distribution: Properties and estimation. Pak. J. Stat. 2017, 33, 37-61.

8. Tahir, M.H.; Cordeiro, G.M.; Ali, S.; Dey, S.; Manzoor, A. The inverted Nadarajah-Haghighi distribution: Estimation methods and applications. J. Stat. Comput. Simul. 2018, 88, 2775-2798. [CrossRef]

9. Hassan, A.S.; Abd-Allah, M. On the Inverse Power Lomax Distribution. Ann. Data Sci. 2018, 6, 259-278. [CrossRef]

10. Hassan, A.S.; Mohamed, R.E. Parameter estimation for inverted exponentiated Lomax distribution with right censored data. Gazi Univ. J. Sci. 2019, 32, 1370-1386.

11. Hassan, A.S.; Elgarhy, M.; Ragab, R. Statistical properties and estimation of inverted Topp-Leone distribution. J. Stat. Appl. Probab. 2020, 9, 319-331.

12. Hassan, A.S.; Elgarhy, M. Kumaraswamy Weibull-generated family of distributions with applications. Adv. Appl. Stat. 2016, 48, 205-239. [CrossRef]

13. Cordeiro, G.M.; Alizadeh, M.; Marinho, P.R.D. The type I half-logistic family of distributions. J. Stat. Comput. Simul. 2015, 86, 707-728. [CrossRef]

14. Al-Shomrani, A.; Arif, O.; Hanif, S.; Shahbaz, M.Q.; Shawky, A. Topp-Leone Family of Distributions: Some Properties and Application. Pak. J. Stat. Oper. Res. 2016, 12, 443. [CrossRef]

15. Hassan, A.S.; Hemeda, S.E.; Maiti, S.S.; Pramanik, S. The generalized additive Weibull-G family of probability distributions. Int. J. Stat. Probab. 2017, 6, 65-83. [CrossRef]

16. Hassan, A.S.; Nassr, S.G. Power Lindley-G family of distributions. Ann. Data Sci. 2019, 6, 189-210. [CrossRef]

17. Hassan, A.S.; Elgarhy, M.; Ahmad, Z. Type II generalized Topp-Leone family of distributions: Properties and applications. J. Data Sci. JDS 2019, 17, 638-659. [CrossRef]

18. Marshall, A.W.; Olkin, I. A new method for adding a parameter to a family of distributions with applications to the exponential and Weibull families. Biometrika 1997, 84, 641-652. [CrossRef]

19. Hassan, A.S.; Elgarhy, M.; Shakil, M. Type II half logistic family of distributions with applications. Pak. J. Stat. Oper. Res. 2017, 13, $245-264$. 
20. Hassan, A.S.; Elgarhy, M.; Haq, M.A.; Alrajhi, S. On type II half logistic Weibull distribution with applications. Math. Theory Modeling 2019, 19, 49-63.

21. Haq, M.A.; Almarashi, A.M.; Hassan, A.S.; Elgarhy, M. Type II half logistic Rayleigh: Properties \& estimation based on censored samples. J. Adv. Math. Comput. Sci. 2018, 19, 1-19.

22. Hassan, A.S.; Elgarhy, M.; Mohamed, R.E. Statistical properties and estimation of type II half logistic Lomax distribution. Thail. Stat. 2020, 18, 290-305.

23. Zeineldin, R.A.; Haq, M.A.U.; Hashmi, S.; Elsehety, M.; Elgarhy, M. Type II half logistic Kumaraswamy distribution with applications. J. Funct. Spaces 2020, 2020, 1-15. [CrossRef]

24. Bantan, R.; Hassan, A.S.; Elsehetry, M.; Golam Kibria, B.M. Half-logistic xgamma distribution: Properties and estimation under censored samples. Discret. Dyn. Nat. Soc. 2020. [CrossRef]

25. McIntyre, G. A method for unbiased selective sampling, using ranked sets. Aust. J. Agric. Res. 1952, 3, 385-390. [CrossRef]

26. Zamanzade, E. New ranked set sampling for estimating the population mean and variance. Hacet. J. Math. Stat. 2015, 46, 1891-1905. [CrossRef]

27. Haq, A.; Brown, J.; Moltchanova, E.; Al-Omari, A.I. Paired Double Ranked Set Sampling. Commun. Stat. Theory Methods 2015, 45, 2873-2889. [CrossRef]

28. Al-Omari, A.I.; Almanjahie, I.M.; Hassan, A.S.; Nagy, H.F. Estimation of the stress-strength reliability for exponentiated pareto distribution using median and ranked set sampling methods. Comput. Mater. Contin. 2020, 64, 835-857. [CrossRef]

29. Bantan, R.; Hassan, A.S.; Elsehetry, M. Zubair Lomax distribution: Properties and estimation based on ranked set sampling. Comput. Mater. Contin. 2020, 65, 2169-2187. [CrossRef]

30. Hassan, A.S.; Al-Omari, A.; Nagy, H.F. Stress-strength reliability for the generalized inverted exponential distribution using MRSS. Iran. J. Sci. Technol. Trans. A Sci. 2021, 45, 641-659. [CrossRef]

31. Mathematica, Version 9.0; Wolfram Research Inc.: Champaign, IL, USA, 2012.

32. Lee, P.N.; Gross, A.J.; Clark, V.A. Survival distributions: Reliability applications in the biomedical sciences. J. R. Stat. Soc. Ser. C Appl. Stat. 1976, 25, 303. [CrossRef]

33. Linhart, H.; Zucchini, W. Model Selection; Wiley: New York, NY, USA, 1986.

34. Mahadavi, A.; Kundu, D. A new method of generating distribution with an application to exponential distribution. Commun. Stat. Theory Methods. 2017, 46, 6543-6557. [CrossRef]

35. Dey, S.; Ghosh, I.; Kumar, D. Alpha power transformed Lindley distribution: Properties and associated inference with application to earthquake data. Ann. Data Sci. 2019, 6, 623-650. [CrossRef]

36. Alrajhi, S.H. The odd Fréchet inverse exponential distribution with application. J. Nonlinear Sci. Appl. 2019, 8, 535-542. [CrossRef]

37. Elgarhy, M.; Alrajhi, S.H. The odd Fréchet inverse Rayleigh distribution: Statistical properties and applications. J. Nonlinear Sci. Appl. 2019, 12, 291-299. [CrossRef]

38. Aarset, M.V. How to identify a bathtub hazard rate. IEEE Trans. Reliab. 1987, 36, 106-108. [CrossRef] 